\title{
Sitzung vom 22. März 1875.
}

Vorsitzender: Hr. A. Beringer, Vorstandsmitglied.

Nach Genehmigung des Protocolls der letzten Sitzung wurden gewählt als auswärtige Mitglieder die Herren:

Dr. G. Garnelutti in Giessen,

Georg Warncke, Assist. am technol. Institut

C. E. Wolff, Assistent am chem. Laboratorium in

Leonh. Limpach, Apotheker - - $\}$ Würz-

$\begin{array}{lll}\text { Wm. Homann, stud. chem. } & - & - \\ \text { Georg Schanz, stud. chem. - } & - & \text { burg, }\end{array}$

L. Belli, Laboratorium des Polytechnicums zu München,

E. Cleminshaw, Belvidere, London S. E.,

Dr. A. Steiner, Unterneckargasse 82, Heidelberg,

Eugen Esslinger, Chemiker, Bleicherweg, Zürich,

A. Archer, Techuiker, Laboratorium von Prof. Pohl in Wien,

Georg Vortmann, Chemiker der Fabrik chemischer Produkte in Hrastnigg, Südbahn, Steiermark,

Alb. Münzig, Fabrikbesitzer in Heilbronn,

U. Grubenmann, Professor der Cantonschule in Frauenfeld, Canton Thurgau, Schweiz,

Constantin Councler, Laboratorium des Hrn. Prof.

Felix Allihn, \} Wiedemann in Leipzig,

Roman Wekker, Zuckerfabrikdirector in Koszowata, Gouvernement Kiew, Russland,

Siegfried Stein, Kaufmann, Clemensstr. 4,

$\left.\begin{array}{l}\text { Ferd. Rotering, stud. chem., Chem. Institut, } \\ \text { P. Hunaeus, stud. chem., Chem. Institut, }\end{array}\right\} \begin{gathered}\text { in } \\ \text { Bonn. }\end{gathered}$

Für die Bibliothek sind eingegangen:

Als Geschenk:

v. Gorap-Besanez: Lehrbuch der physiologischen Chemie. 3. Aufl. Braunschweig 1874 u. 1875.

Arcangelo Scacchi: Sulle forme cristalline di alcuni compositi di Toluene. Napoli 1870. (Von Hrn. Prof. Körner.)

Berichte d. D. Chem. Gesollschaft. Jahrg. VHI. 
W. Körner: Fatti per servire alla determinazione del luogo chimico nelle sostanze aromatiche. Palermo 1869. (Vom Verf.)

W. Körner: Studj sull' isomeria delle cosi dette sostanze aromatiche a 6 atomi di carbonio. (Vom Verf.)

Elwyn Waller: Report on Disinfection and Disinfectants. Cambridge, U.S.A., 1874. (Vom Verf.)

C. Matthias: Ueber Derivate der Phosphenylsäure. Inaug.-Dissert. Zürich 1875. (Von Hrn. Loth. Meyer.)

C. F orst: Beitrüge zur Kenntniss der Hydrobenzoüns. Inaug.-Dissert. Bonn 1874. (Vom Verf.)

Annali dei Regii Istituti tecnico e nautico di Livorno. Anno 1871/72; anno 1872/73.

Ferner folgende Zeitschriften im Austausch:

Journal der Russischen chemischen Gesellschaft. Bd. VII, No. 1, 2.

Chemisches Centralblatt. No. 10, 11.

Deutsche Industriezeitung. No. 10, 11.

Journal für praktische Chemie. Bd. 10, Heft 10.

Verhandlungen der K. K. geolog. Reichsanstalt. No. 3.

Centralblatt für Agriculturchemie. Heft 3 (März).

Archives des sciences phys. et nat. Génève. No. 206 (Février).

Archives néerlandaises t. IX, livrais 4, 5 .

Maandblad voor Naturrwetenschappen. No. 4.

Bulletin de la Société chimique de Paris. No. 6.

Revue scientifique. No. 37, 38.

Moniteur scientifique Quesneville. Mars.

Gazzetta chimica italiana. Anno V (1875). Fasc. 1 e 2.

Durch Kauf:

Polytechnisches Journal von Dingler. Bd. 215. No. 3.

Comptes rendus. No. 10.

\section{Mittheilungen.}

\section{H. Limpricht: Ueber Löslichkeitsbestimmungen.}

(Eingegangen am 17. März; vorgetrag. in der Sitzung von Hrn. Oppenheim.)

Die Bestimmung der Löslichkeit ist in vielen Fällen sehr geeignet über die Identität oder Verschiedenheit namentlich isomerer Verbindungen sich ein Urtheil zu bilden. Bei den Salzen z. B., bei welchen Schmelzpunkts - und Siedepunktsbestimmungen nicht anwendbar sind, bei welchen sehr oft die Krystallform nicht so ausgebildet ist, dass sie mit Leichtigkeit sicher erkannt werden kann, und bei welchen auch der Krystallwassergehalt ein wechselnder sein kann, bietet die Bestimnrung ihrer Löslichkeit ein nicht genug zu schätzendes Criterium. A ber wenn die Resultate genau sein sollen, muss die Löslichkeit in andrer Weise bestimmt werden, als es bisher in der Regel geschehen ist. Es genügt nicht eine Lösung nur einige Tage bei constanter Temperatur stehen zu lassen und dann in einem gemessenen Volumen den Gebalt an Gelöstem festzustellen. Wie ich unten an einigen Beispielen zeigen werde krystallisirt nach Wochen noch immer von der Substanz heraus und ich gelangte sehr oft deshalb nicht $z u$ einem befrie- 